\title{
Moodle - UFPR: um redesign de interface centrado no usuário Moodle - UFPR: a user-centred interface redesign
}

\author{
Juliana Bueno, Karina de Abreu Antoniolli \& Letícia Lôndero Heleno
}

moodle, interface, dcu

Esse artigo apresenta o processo e resultados de um projeto de 6 meses realizado a partir de uma parceria entre a CIPEAD/UFPR (Coordenação de Integração de Políticas de Educação a Distância da Universidade Federal do Paraná) e o Departamento de Design da Universidade Federal do Paraná, para reestruturar a interface e interação do Ambiente Virtual de Aprendizado (AVA) Moodle-UFPR, colocando a experiência do usuário como foco e contemplando sua diversidade no escopo acadêmico. Como processo de design, foi tomada como base a estrutura dos elementos de um sistema digital apontada por Garrett, com o objetivo de garantir uma boa experiência do usuário dentro dos níveis: estratégia, escopo, estrutura, esqueleto e superfície. Reuniões regulares com o time CIPEAD/UFPR, avaliação especializada da atual interface da plataforma, grupo focal com professores e alunos da plataforma e análise de similares são os principais passos metodológicos no nível estratégico. Com isso, são considerados aspectos chave para a nova interface: interatividade; simplicidade; intuitividade; acessibilidade; acesso rápido; uniformização; identidades visuais bem definidas para os diferentes cursos. Como resultado, o time apresenta um protótipo não funcional e guia de estilo da nova interface e projeto de interação do Moodle-UFPR para implementação por parte do time CIPEAD/UFPR. O projeto deve passar por validação com usuários em potencial para ter sua efetividade garantida.

moodle, interface, ucd

This paper presents the process and the results of a 6-month project, a partnership between CIPEAD/UFPR (Coordination of Integration of Distance Learning Education Policies of the Federal University of Paraná, Brazil) and the Design Department of UFPR to reorganize the interface and interaction of the Virtual Learning Environment (VLE) Moodle-UFPR, having user experience as a focus and contemplating its diversity in the academic scope. As a design process, the structure of elements of a digital system pointed out by Garrett was taken as a basis, in order to guarantee a good user experience in the following levels: strategy, scope, structure, skeleton and surface. Systematic meetings with CIPEAD/UFPR team, expert evaluation of the current Moodle-UFPR interface, Focus Group with MoodleUFPR professors and students and analysis of similar VLEs are the main methodological steps of the strategy level. With that, are considered as the key aspects for the new interface: interactivity; simplicity; intuitiveness; accessibility; quick access; standardization; well-defined visual identity for the different courses. As a result, the team presents a non-functional prototype and style guide of the new MoodleUFPR interface and interaction project for implementation by CIPEAD/UFPR team. The project must go through validation of its potential users so that its effectiveness is guaranteed.

\section{Introdução}

Educação a Distância (EAD), como assinala Filatro (2007), representa um formato de ensino desenvolvido e utilizado com o propósito de democratizar e ampliar a facilidade no acesso ao conhecimento. Entre tecnologias que fazem a prática do EAD ser viável, o Ambiente Virtual de Aprendizado (AVA) destaca-se. Se bem aproveitado, o AVA é um ambiente rico de significados, onde pessoas e objetos técnicos interagem, potencializando a aquisição de conhecimento e, por consequência, aprendizado (Almeida, 2006).

Anais do 9 CIDI e 9 CONGIC

Luciane Maria Fadel, Carla Spinillo, Anderson Horta, Cristina Portugal (orgs.)

Sociedade Brasileira de Design da Informação - SBDI

Belo Horizonte | Brasil | 2019

ISBN 978-85-212-1728-2
Proceedings of the 9thCIDI and 9thCONGIC

Luciane Maria Fadel, Carla Spinillo, Anderson Horta,

Cristina Portugal (orgs.)

Sociedade Brasileira de Design da Informação - SBDI

Belo Horizonte | Brazil | 2019

ISBN 978-85-212-1728-2 
Além da convergência de mídias aliadas a internet, os AVAs agregam uma multiplicidade de linguagens (sons, imagens, fotos e textos) através de comunicação com atividades síncronas (chat, videoconferência) e assíncronas (fórum, wiki, blog e email) (Silva, 2006). Por isso, muitas escolas e universidades têm feito uso de AVAs para o ensino a distância. Dentre os AVAs disponíveis, o mais popular é o Moodle, sendo amplamente utilizado no contexto brasileiro. Sua popularidade se dá ao fato de conter todas as características citadas, além de ser uma ferramenta de código aberto, assim, pode ser utilizada em sua configuração padrão e permite alterações em sua interface (Moodle, 2018).

Neste contexto, a Universidade Federal do Paraná (UFPR) faz uso do Moodle para seu ensino a distância, sendo gerenciado pela Coordenadoria de Integração de Políticas de Educação a Distância (CIPEAD/UFPR), oferecendo cursos de graduação, extensão, aperfeiçoamento e especialização. Com isto, estima-se que o Moodle-UFPR abranja um público de mais de 30 mil usuários no contexto acadêmico da universidade. Entretanto, assim como acontece com outros AVAs utilizados em outras instituições de ensino, sua abrangência não garante sua efetividade e nem uma boa experiência de usuário, como relatado em pesquisa preliminar da CIPEAD/UFPR. Isto porque, como indica Garrett (2011), frequentemente, muitos sistemas digitais são desenvolvidos sem considerar o Design Centrado no Usuário e o Moodle-UFPR não é uma exceção.

A fim de reverter este contexto, pautando-se em literatura pertinente ao tema, este artigo apresenta o processo de design bem como os resultados de um projeto de 6 meses, no qual de uma parceria entre a CIPEAD/UFPR e o Departamento de Design da UFPR, chegou-se a uma proposta de redesign da interface e da interação do Moodle da UFPR, tendo a experiência do usuário como foco e contemplando a sua diversidade no âmbito acadêmico.

Por isso, por exemplo, o Design Universal (DU) foi tido como premissa. Pois, o DU prescreve que os sistemas digitais (como um AVA, por exemplo) devem ser de fácil utilização, com uma interface acessível ao usuário (flexível, consistente, simples e intuitiva), adaptável a qualquer ambiente e tecnologicamente adequada aos recursos disponíveis (Sonza et al., 2013).

Sendo assim, quanto à estrutura, o artigo traz: (1) o referencial teórico; (2) o processo de Design Centrado no Usuário; (3) os resultados do projeto (protótipo não funcional e guia de estilo) e; por último, (4) as considerações finais.

\section{Referencial Teórico}

\section{AVAs}

Gabardo, Quevedo e Ulbricht (2010) salientam que, a Educação a Distância tem como meta a atualização de conhecimentos, formação profissional e o desenvolvimento de competências. Atualmente, dentre as várias possibilidades de EaD tem-se os AVAs.

Segundo Pereira et al. (2007), AVA é a nomenclatura adotada no Brasil para designar os softwares que cumprem a função de mediar o ensino a distância veiculado através da internet ou espaço virtual. Tem como principal função permitir a interação entre os "atores do processo educativo" (Pereira et. al, 2007, p.4). A qualidade deste ambiente virtual de aprendizagem depende do envolvimento de cada ator durante a execução deste processo.

O sistema da Universidade Aberta do Brasil - UAB projeto da CAPES-MEC (que também gerencia o ensino a distância da UFPR) tem como AVA o Moodle. O seu desenvolvimento tem por objetivo o gerenciamento do aprendizado e o trabalho colaborativo em ambiente virtual.

O Moodle possibilita a criação e gestão de cursos online, grupos de trabalho e comunidades de aprendizagem (Moretto \& Ulbricht, 2011). Desta forma, como qualquer outro AVA, ele é um espaço em que o sujeito, em interação com objetos de conhecimento, torna-se o centro do processo de aprendizagem (Almeida, 2006). Entretanto, sabe-se que assim como ocorre no 
com a maioria dos sistemas digitais, o usuário muitas vezes não é inserido no processo de desenvolvimento, o que acarreta em falhas e problemas de interface e interação que atrapalham ou até inviabilizam o acesso do usuário a determinado sistema. Outra questão importante colocada por Pereira (2007) é que o AVA, por mais que tenha potencial para atender a um variado espectro de público, tradicionalmente utiliza-se de um ambiente homogêneo para qualquer usuário. Como ressalta o mesmo autor, o AVA deveria ser universal e atender às exigências de acessibilidade, de forma a permitir o acesso e a utilização por diversos públicos. Tais questões chamam a atenção para a importância de Design Centrado no Usuário.

\section{DCU}

Conforme a ISO 9241-210 (2010), o Design Centrado no Usuário é uma abordagem para o desenvolvimento de sistemas interativos que visa tornar os sistemas mais úteis e com boa usabilidade ao focar nos usuários, suas necessidades e requisitos e ao aplicar conhecimento e técnicas da ergonomia/fatores humanos e da usabilidade. A ISO 9241-210 ainda prevê que, para a concepção de uma projeto DCU, além dos usuários, sejam envolvidos profissionais de diferentes competências (designers, programadores, representantes de usuários finais do sistema e representantes de usuários indiretos, entre outros), tornando-se um projeto multidisciplinar.

Neste contexto, como ressalta Garrett (2011), "a prática de criar experiências de usuário atraentes e eficientes é chamado design centrado no usuário. O conceito de DCU é muito simples: leve o usuário em conta a cada passo do caminho você desenvolve seu produto". Para o autor, ainda, tudo o que o usuário experimenta deve ser o resultado de uma decisão consciente de quem desenvolve o sistema, nada deve ser por acidente.

Já o envolvimento dos usuários pode ser: informativo, consultivo ou participativo e este grau de envolvimento influencia o quanto o usuário tem poder de decisão sobre todos os aspectos do desenvolvimento do sistema (Cybis, Betiol \& Faust, 2015). Lembrando que, como enfatiza Nielsen (2003) "projetista não é usuário" e "usuário não é projetista", por isso, é razoável que o envolvimento ocorra como uma combinação de busca de informação, consulta e coautoria.

Então, mais que decisões estéticas, o DCU permite ter uma abrangência de todo o cenário. O foco no usuário é mais do que simplesmente discutir como será a aparência do sistema digital, o DCU permite examinar quanto um aplicativo é eficiente para atingir o propósito ao que foi concebido (Lowdermilk, 2013).

\section{Elementos da estrutura de Garrett}

Garrett (2011) desenvolveu, a partir da perspectiva do DCU, uma Estrutura de Componentes Digitais, composta por cinco níveis (estratégia, escopo, estrutura, esqueleto, superfície), que vão do nível mais abstrato da informação ao mais concreto. Cada nível depende diretamente da anterior, e isso possibilita que o desenvolvimento do projeto se mantenha alinhado ao que foi decidido inicialmente (Figura 1). Entre os níveis de escopo e esqueleto, existe uma divisão central que confere a separação entre produto como funcionalidade e produto como informação, isso permite desenvolver esses dois aspectos efetivamente em um mesmo plano. São os cinco níveis:

- Estratégia: o nível de estratégia incorpora não apenas o que os desenvolvedores querem do projeto (Objetivos do Produto), mas o que os usuários desejam (Necessidades do Usuário), portanto, essa etapa é essencial para uma experiência do usuário de qualidade.

- Escopo: a estratégia se traduz em escopo no campo da funcionalidade para o desenvolvimento de especificações funcionais: uma descrição detalhada do conjunto de características do produto. Quanto à informação, o escopo toma forma de requisitos de conteúdo: uma descrição dos muitos elementos de conteúdo que serão necessários. 
- Estrutura: na funcionalidade, o escopo ganha estrutura pelo Design de Interação, no qual é definido como o sistema deverá se comportar em resposta ao usuário. Quanto aos recursos de informação, a estrutura é a arquitetura da informação, ou seja, a organização dos elementos de forma a facilitar a compreensão humana.

- Esqueleto: o esqueleto é a concretização das etapas anteriores, ele se traduz no layout da interface, na organização e posicionamento dos elementos e informações. Esse plano desenvolve a navegação e interação do usuário com a interface juntamente às informações que deverão estar contidas no produto.

- Superfície: a superfície é o nível mais concreto do desenvolvimento, constituído por elementos percebidos pelos usuários e as sensações causadas por eles (imagens, cores, textos, boxes, etc). Essa é a tradução da experiência sensorial do usuário com o produto final.

Figura 1: estrutura proposta por Garrett (2011).

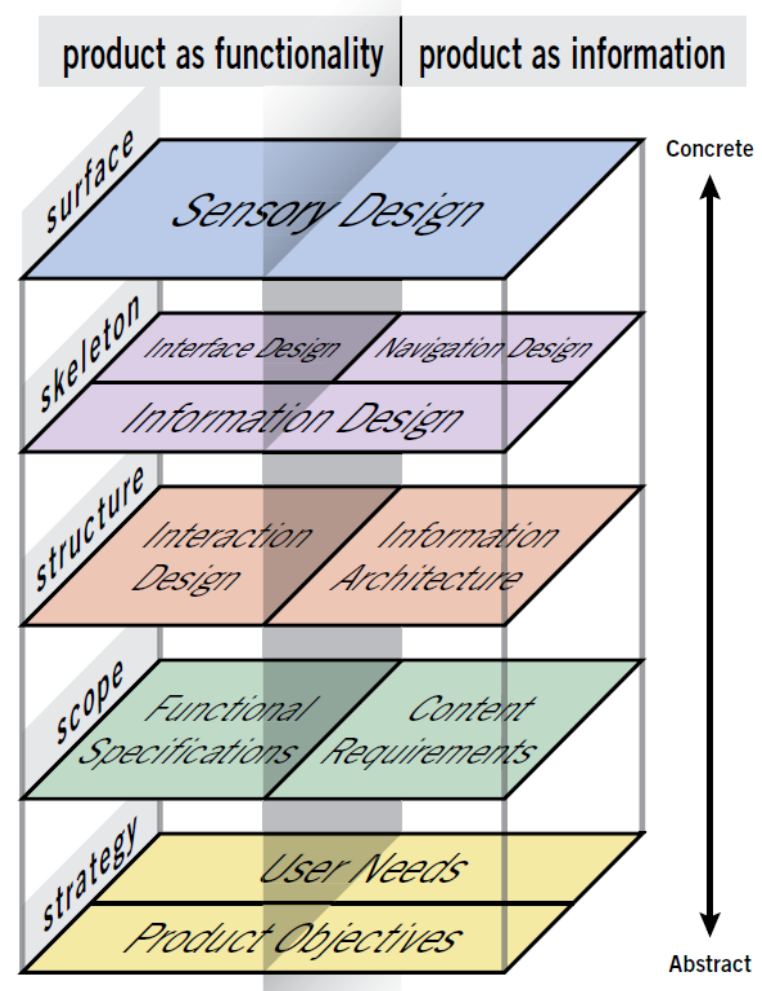

\section{Design Universal}

Segundo a NCSU (1996), o Design Universal busca gerar ambientes, produtos, serviços, programas e tecnologias acessíveis de forma a atender o maior número de pessoas, na maior extensão possível, sem a necessidade de adaptação ou design especializado. Tendo como pensamento sistemas digitais acessíveis à todas as pessoas, Sarah e Quesenbery $(2013$, p. 5) propuseram um framework com guidelines e estratégias para promover experiências acessíveis para a acessibilidade ser incorporada no processo de design:

- Pessoas primeiro: design para diferenças. Sites e aplicativos devem ser feitos com as necessidades do público em mente;

- Propósito claro: guias bem definidas. Pessoas se divertem mais com produtos que são feitos especialmente para o público-alvo e com metas bem definidas. 
- Estruturas sólidas: construa para padrões. As pessoas se sentem mais confiantes usando o design quando ele é estável, robusto e seguro.

- Interação fácil: tudo funciona. Pessoas podem usar o produto através de todos os modos de interação e uma grande variedade de dispositivos.

- Wayfinding útil: guias para os usuários - Pessoas podem navegar um site, sistema ou aplicação, seguindo indicações auto-explicativas.

- Apresentações claras: dar significado - Pessoas podem perceber e entender os elementos de design.

- Linguagem simples: cria uma conversa - As pessoas conseguem ler, entender e usar as informações.

- Mídia acessível: suporta várias mídias - As pessoas podem entender e usar as informações de mídia, como por exemplo imagens, áudio, vídeo, animações e apresentações.

- Usabilidade universal: cria encanto. As pessoas podem na experiência e em suas metas próprias porque o produto antecipa as suas necessidades.

Todos os pressupostos trazidos na fundamentação teórica foram cruciais para as tomadas de decisão explicitadas na sessão do Método, a seguir.

\section{Processo de design}

Desde o primeiro contato dos participantes do projeto, os quais vinham do Departamento de Design da UFPR e da CIPEAD/UFPR, ficou acordado que a perspectiva do Design Centrado no Usuário era o ponto chave para o redesign da interface do Moodle-UFPR (mesmo sendo um projeto de curta duração).

Então, a equipe de Design formada por uma professora especialista na área, uma designer e uma estudante de Design Gráfico da UFPR, estabeleceram um cronograma de trabalho e, como processo de design, a estrutura dos elementos de um sistema digital apontado por Garrett (2011) foi tomada como base, a fim de garantir uma boa experiência do usuário e por contemplar todos os níveis necessários ao desenvolvimento do projeto: estratégia, escopo, estrutura, esqueleto e superfície. A seguir será detalhado como foram trabalhados cada um dos níveis.

\section{Etapa 1 - Estratégia}

Desta maneira, para a definição do nível estratégico do projeto de redesign são indicados como principais passos:

- Avaliação especialista (do design de interação e da informação) da atual interface do Moodle-UFPR;

- Reuniões regulares com a equipe responsável pela implementação da interface do projeto, para melhor compreender a distribuição dos cursos e; possibilidades e restrições com relação ao uso do sistema;

- Análise de AVAs similares, para conhecer o que outras plataformas têm para oferecer no que diz respeito à organização da informação e design de interface;

- Grupo Focal com professores e alunos (usuários) para melhor entender suas dificuldades e expectativas quanto à interface, organização e gerenciamento dos cursos.

O Moodle-UFPR é uma plataforma baseada em informação e, portanto, o redesign foi focado na reorganização destes elementos para um melhor entendimento por parte de professores e estudantes. Para tanto, era crucial entender como o Moodle-UFPR funcionava e 
é apresentado para os usuários no momento atual. Vale explicitar que, por mais que muitas instituições optem por oferecer a interface padrão do Moodle (como no caso da UFPR), a plataforma, atualmente, é totalmente customizável e responsiva.

Assim, nesta primeira etapa foi feita uma avaliação especializada (de design de interação e informação) da atual plataforma (em forma de julgamento de valor) pelas 3 participantes da equipe de Design descrita em forma de relatório.

Ainda, ocorreram encontros regulares com a equipe da CIPEAD/UFPR, no intuito de reconhecer possibilidades e restrições em relação ao uso do sistema e distribuição dos cursos. A equipe da CIPEAD/UFPR era formada pela coordenadora do projeto, a responsável pelo Moodle-UFPR e o engenheiro de software responsável pelas implementações.

A figura 2 apresenta algumas telas da interface atual em um dos cursos oferecidos no Moodle-UFPR. Deve ser notado que a interface atual é baseada na configuração padrão oferecida pela plataforma e nenhuma consulta ao usuário (professores e alunos) foi feita anteriormente.

Figura 2: screenshots da interface atual do Moodle-UFPR.

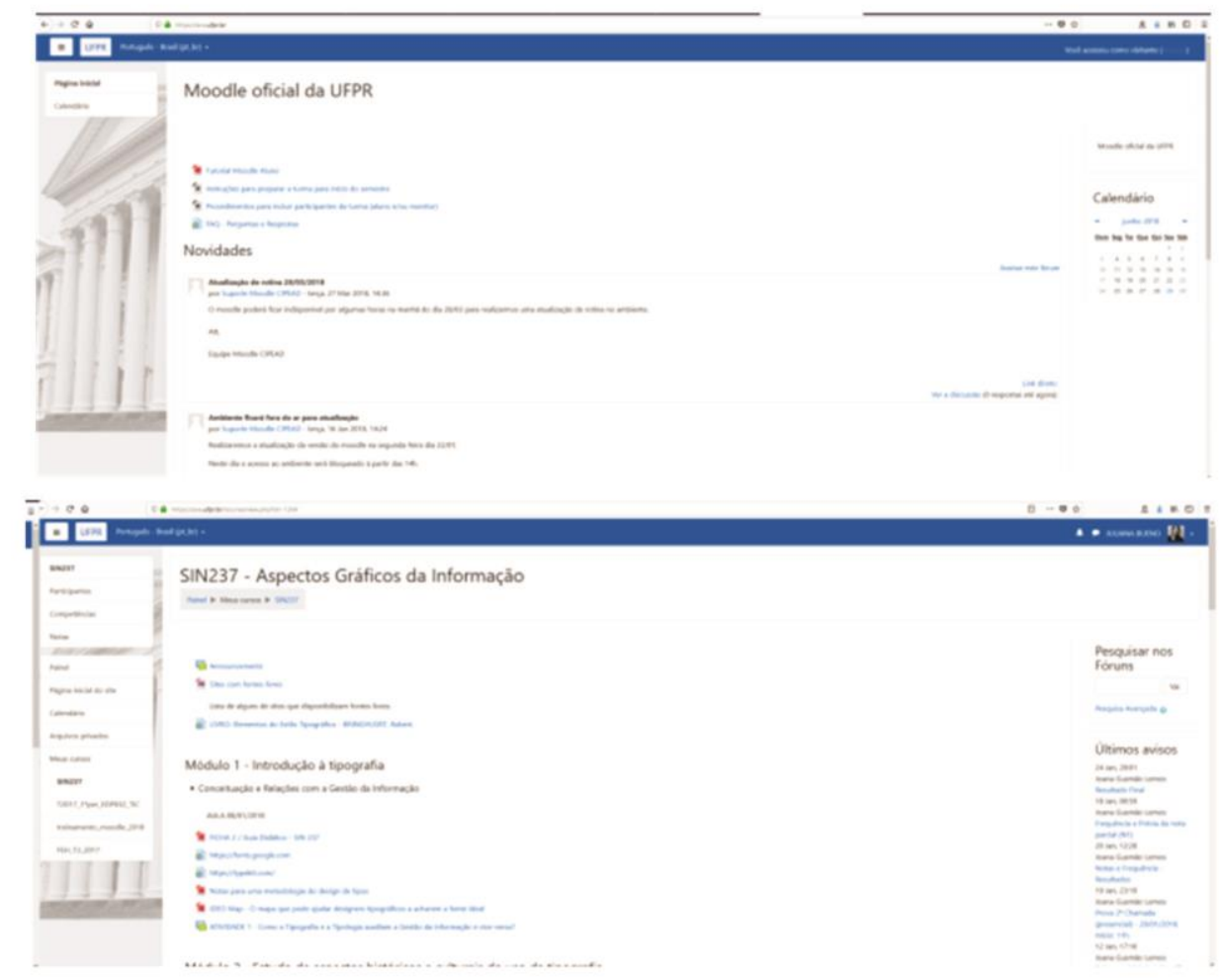

Juntamente com estes primeiros passos, também foi realizada a análise de quatro AVAs similares, para compreender o que outras plataformas têm a oferecer no quesito organização da informação e design da interface. Tais AVAs são plataformas brasileiras de estudo prévestibular. Embora não sejam uma competição direta do Moodle-UFPR, também possuem diferentes cursos, matérias e divisão por tópicos, e precisam apresentar tais materiais bem organizados para melhor assimilação do conteúdo contido na plataforma. Os quatro AVAs foram: Biologia Total, Descomplica, Me Salva! e Stoodi (Figura 3).

Figura 3: similares analisados. 


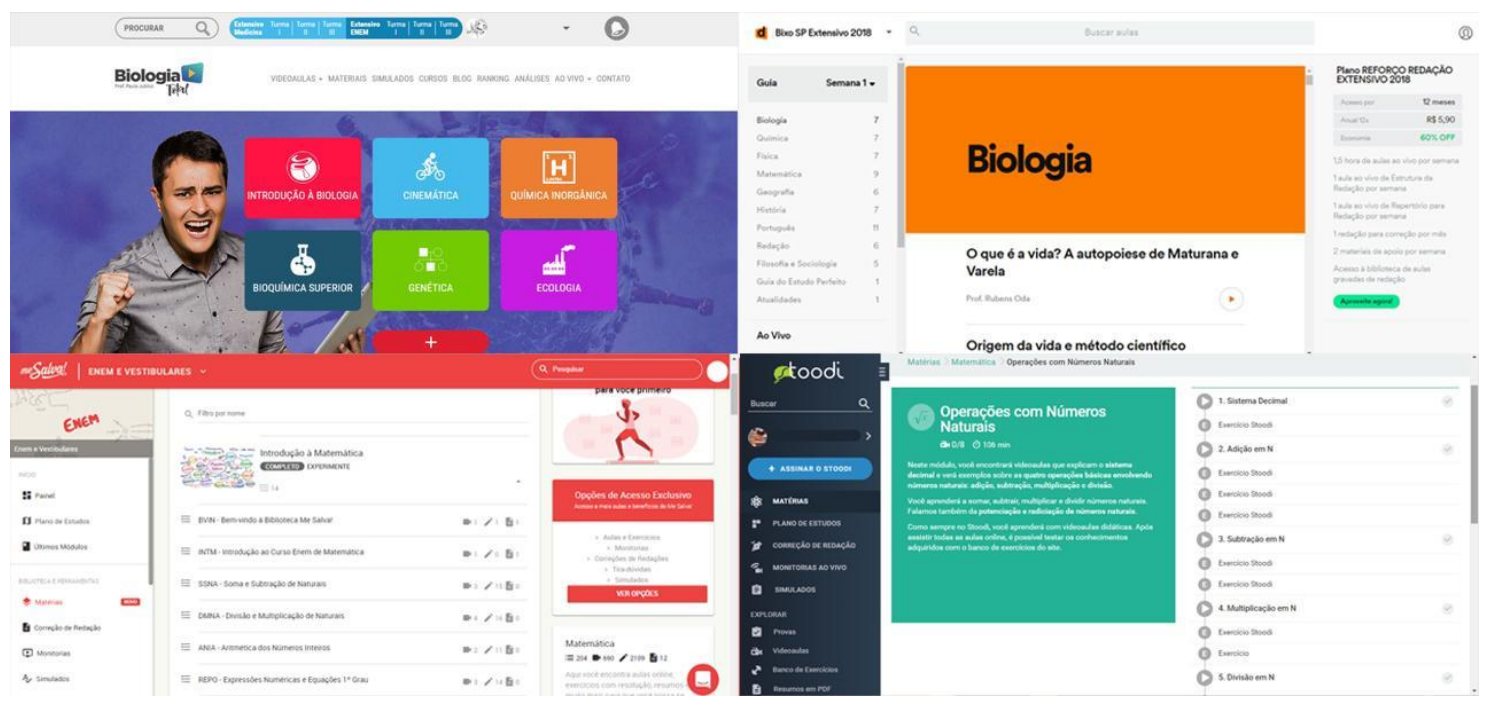

Com isto feito, o projeto sendo centrado no usuário, a próxima etapa foi um grupo focal com professores e estudantes que utilizam o Moodle-UFPR, para reconhecer suas dificuldades e expectativas com relação à interface, organização e manejo dos cursos.

Um grupo focal é um método qualitativo, uma dinâmica a ser aplicada em grupos pequenos formados por indivíduos e guiada por um moderador que pode obter como resultado: ideias profundas sobre um tema, padrões ou tendências (Martin \& Hanington, 2013).

Assim, o grupo focal foi proposto com base em Krueger (1994) para ser aplicado em duas sessões distintas de 2 horas cada: uma com professores que possuem cursos no MoodleUFPR e outra com estudantes da UFPR que fazem os cursos, ambas nas dependências da CIPEAD/UFPR. Cada grupo consistiu de 7 a 10 pessoas e aproximadamente 10 perguntas foram feitas, algumas que eram diferentes para professores ou estudantes. As perguntas foram divididas em questões abertas, introdutórias, transitórias, chave e final:

Questões abertas

1. Qual seu nome e em que situação você está utilizando a plataforma do Moodle em seu contexto de ensino/aprendizagem?

1.1 No caso de aulas/cursos dados à distância:

Professores: como avaliam o processo e envolvimento na aula/curso? (como é repassado exercícios e trabalhos e consequentemente como são avaliados).

Alunos: como é o envolvimento na aula/curso?

2. Em qual dispositivo você interage com a plataforma do Moodle (computador, notebook, tablet ou smartphone)? Se utiliza em dois dispositivos diferentes (Computador e Smartphone, por exemplo), há as mesmas funcionalidades em ambos?

3. Já utilizaram outras plataformas similares ao Moodle? Como foi a experiência?

\section{Questões introdutórias}

4. Em sua opinião, qual a funcionalidade do Moodle na utilização em conjunto com as aulas? (No caso de aulas e cursos dados totalmente à distância, perguntar como o Moodle auxilia para que isso seja feito).

Questão transitória

5. Quais as principais dificuldades na interação com a plataforma?

Questões chave

6. Pensando em uma plataforma de ensino qualquer, quais seriam as principais funcionalidades que seriam importantes de terem incorporadas neste tipo de 
plataforma?

7. Pensando na interatividade do professor e aluno, o que seria necessário na plataforma para que a comunicação entre eles fosse efetiva?

8. O que vocês esperam encontrar em uma página inicial de uma plataforma de ensino? (apresentação das funções, menu, cursos e aulas, entre outros).

9. Ao ser introduzido uma nova matéria ou curso dentro da plataforma de ensino, quais informações consideram importantes para sua divulgação? Questão final

10. Para finalizarmos, vocês poderiam nos dizer se esquecemos de abordar algo ou se vocês têm algo a acrescentar ou modificar?

A sessão com professores contou com sete participantes de cursos distintos e teve duração de aproximadamente 2 horas. Já para a sessão com os estudantes, apenas uma aluna do curso de Pedagogia da UFPR compareceu e, então, o grupo focal acabou sendo adaptado para uma entrevista semi estruturada. Vale salientar que, todos os participantes assinaram o Termo de Consentimento Livre e Esclarecido. Assim, a sessão e a entrevista foram gravadas em áudio e em vídeo.

\section{Etapa 2 - Escopo}

Alguns requisitos para o Moodle-UFPR foram pedidos diretamente pela equipe da CIPEAD/UFPR nos encontros iniciais, como: diferenciação por cor de tipos de cursos, mais interatividade e mais acessibilidade. Com esses pedidos mais amplos, algumas modificações específicas para professores, estudantes e tutores foram solicitadas também, uma vez que existem funcionalidades que diferem dependendo do tipo de acesso da pessoa na plataforma.

A partir da aplicação do grupo focal, novos problemas foram apontados pelos professores e alunos, e assim novos requisitos surgiram. Tais requisitos sendo: organizar a ordem cronológica dos cursos que são ofertados e especificar quais ainda estão ativos; aprimorar a aparência dos tópicos em cada curso, assim como o wayfinding dentro da plataforma. Também houveram reclamações no que se refere à página inicial do Moodle-UFPR, a qual não continha as informações sobre o portal, e o porquê de sua existência. Conseqüentemente, pode-se sumarizar como premissas para a nova interface:

- interatividade;

- simplicidade;

- intuitividade;

- acessibilidade;

- acesso rápido;

- padronização;

- identidades visuais bem definidas para as diferentes tipos de cursos.

\section{Etapa 3 - Estrutura}

Após os requisitos serem obtidos, o nível estrutural foi iniciado. Entender o que os usuários precisam, e o que estão acostumados a ver e utilizar, sustentou as decisões estruturais. Com isso, modelos conceituais e convenções para plataformas como o Moodle-UFPR foram trabalhados em conjunto com os requisitos do escopo (Figura 4).

Como Garrett (2011) assinala: "em sites de conteúdo, a arquitetura da informação se concentra em criar esquemas organizacionais e navegacionais que permitam aos usuários se 
mover pelo conteúdo do site de forma eficiente e eficaz", a maneira de organizar informação no Moodle-UFPR foi reordenado. Como o Moodle-UFPR é uma plataforma existente com seu conteúdo, a abordagem Estrutural para a arquitetura da informação foi bottom-up. Tal abordagem inicia com o conteúdo existente e a discussão do nível de Escopo, agrupando conteúdos em categorias de baixo para cima, refletindo os objetivos para o produto e as necessidades dos usuários. Uma abordagem top-down iniciaria com a análise do nível estratégico, nas categorias maiores até chegar às menores, encaixando o conteúdo.

Figura 4: Arquitetura da Informação do Moodle-UFPR.

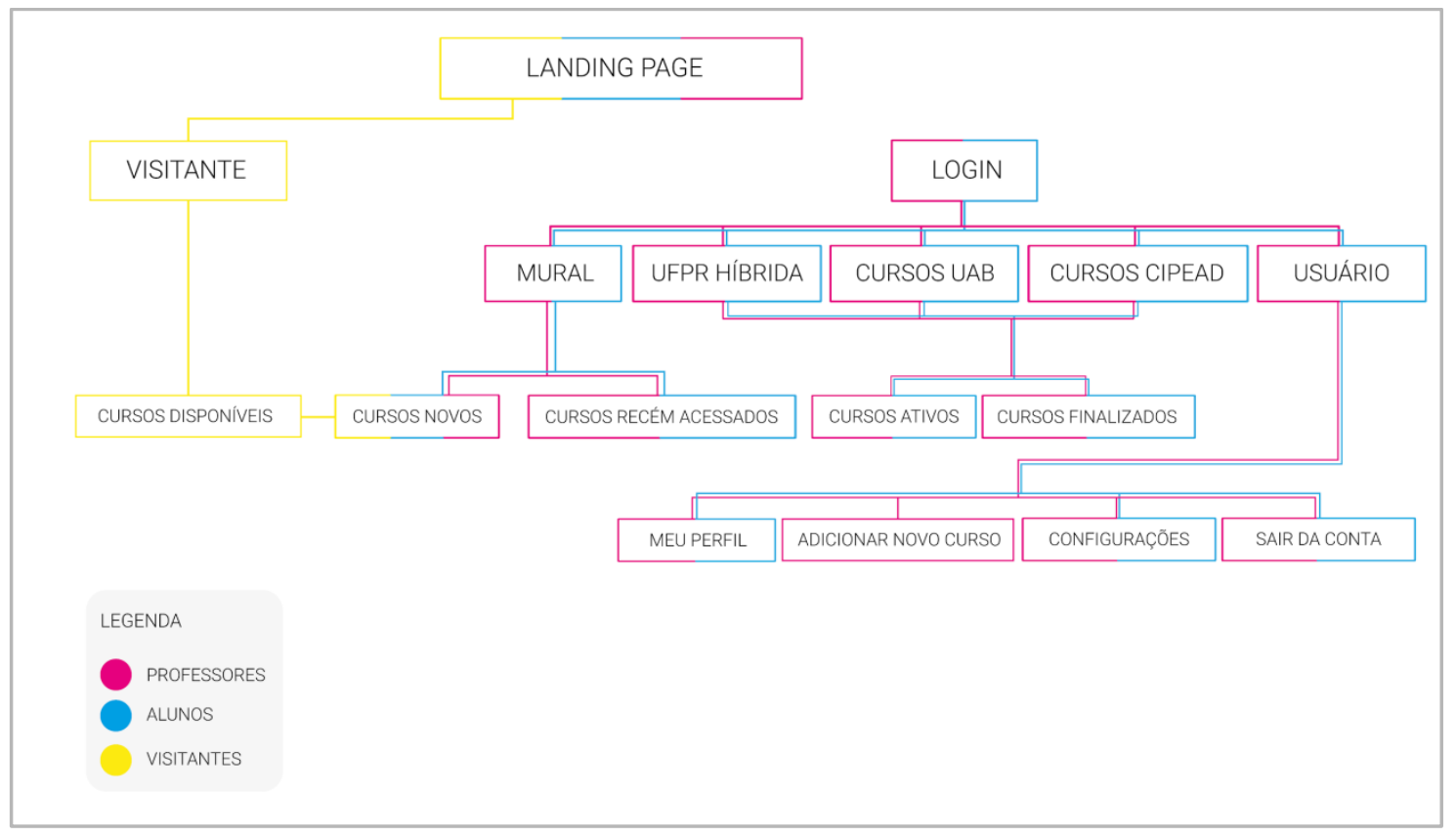

\section{Etapa 4 - Esqueleto}

Para o nível de Esqueleto, os primeiros rascunhos do redesign foram criados. Entendendo como a plataforma funcionaria, tais rascunhos foram refinados em wireframes para as páginas mais importantes: página inicial, de login, o exemplo de um mural, página de curso, perfil e uma nova página para a criação e edição de cursos (Figura 5). Aqui nesta etapa, os princípios da Gestalt foram fundamentais para reestruturar a informação em padrões simples e lógicos (Gomes Filho, 2004; Lupton, 2017).O modo de wayfinding era uma função importante que as equipes de Design e CIPEAD/UFPR deveriam aprimorar, portanto, a navegação por "caminho de pão" e da barra superior foram aperfeiçoadas. 


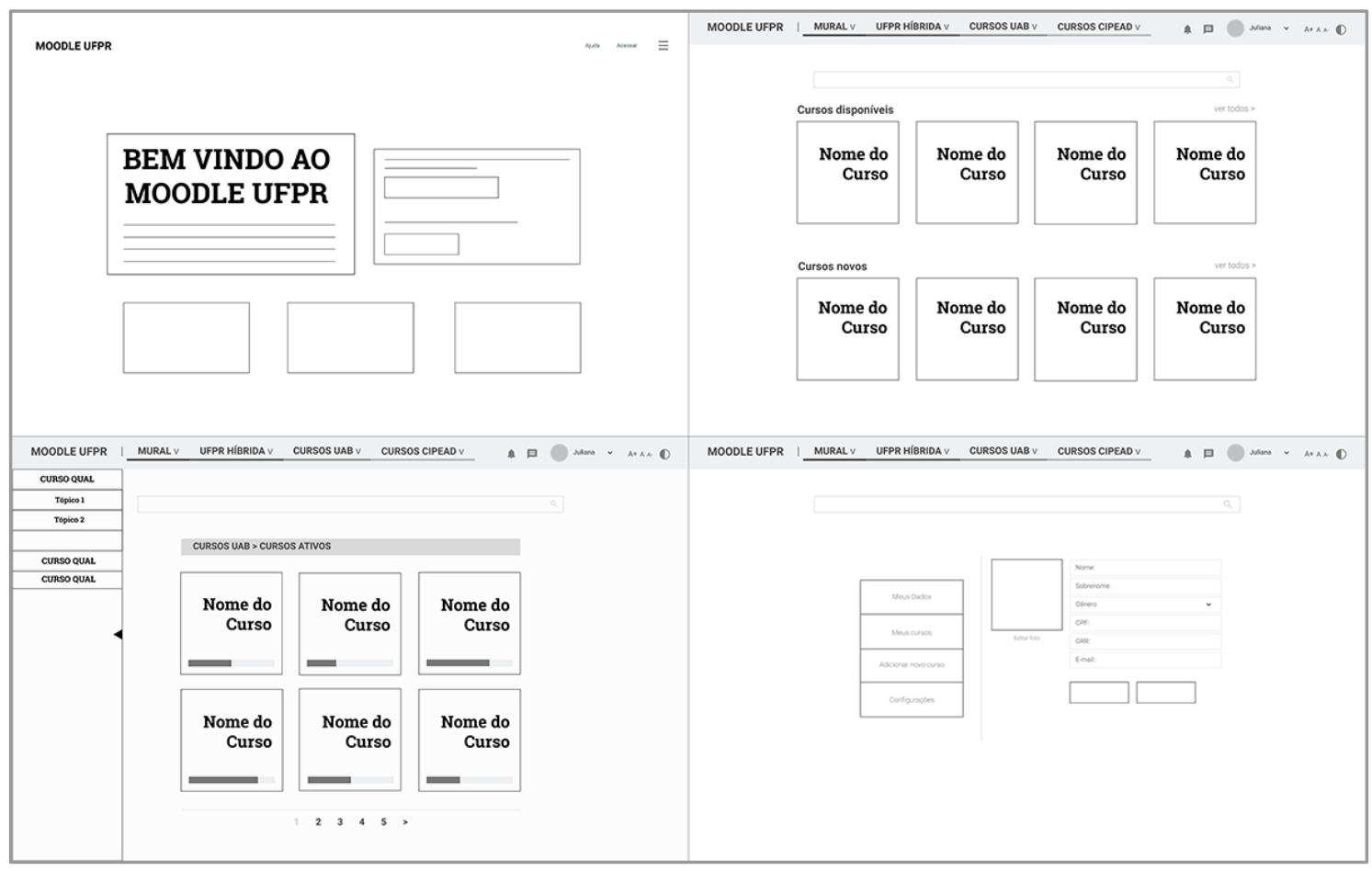

No decorrer do processo de desenvolvimento dos elementos visuais (nível da superfície), telas e paletas de cores foram validadas pelo time CIPEAD/UFPR.

\section{Etapa 5 - Superfície}

Após a elaboração dos wireframes, o nível da Superfície, o visual da plataforma, foi executado. Com os elementos que serão usados nas páginas expressados nos wireframes, cores, fonte e ícones foram definidos, ou seja, trabalhou-se aqui com a linguagem visual. Sendo assim, foram tomados como base os elementos primitivos apontados por Horn (1998) e Mijksenaar (1997).

Como existem diferentes tipos de cursos no Moodle-UFPR, além de sua cor oficial, sete outras foram selecionadas. Estas oito cores (Figura 6) formam a paleta geral do novo visual, possuindo um bom contraste entre si e funcionando para pessoas daltônicas. Incorporada à cada tipo de curso, há uma paleta que parte da cor principal, variando em valor. Após as cores serem validadas coma equipe da CIPEAD/UFPR também foram acrescidas texturas para distinção de cada curso, para reforçar a diferenciação das cores, quando em preto e branco (Figura 7).

As paletas foram constituídas com a ajuda da plataforma Coolors, um gerador de esquema de cores criado por Fabrizio Bianchi. Esta etapa foi realizada para garantir que funcionará para daltônicos também, uma vez que a plataforma consegue simular diferentes tipos de daltonismo. 


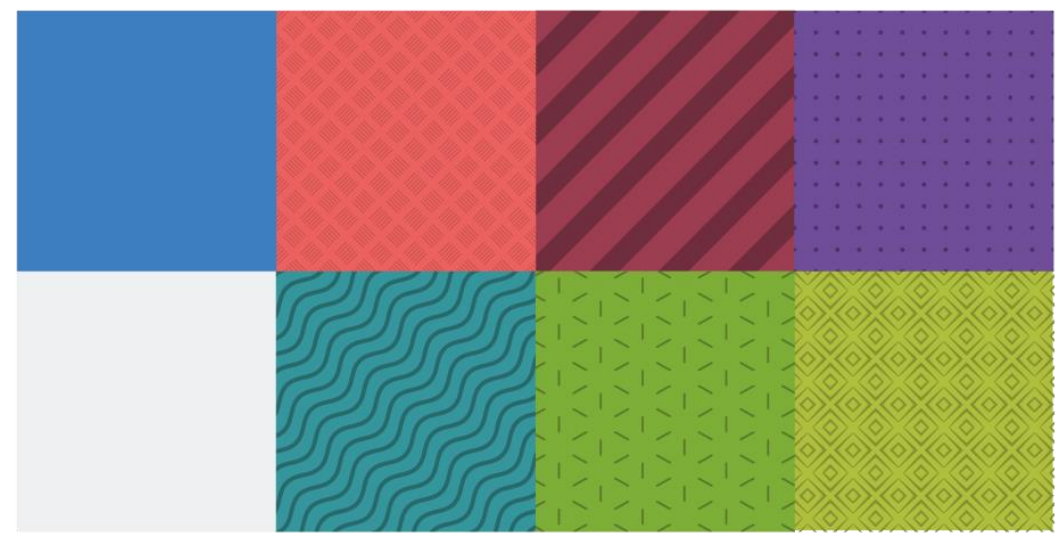

Figura 7: Cores e texturas em preto e branco do Moodle-UFPR.

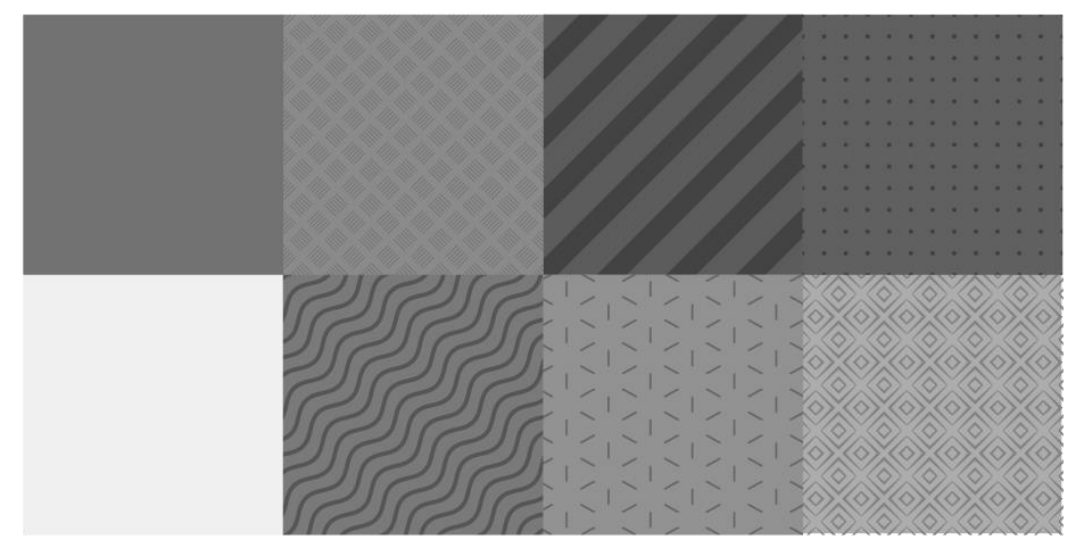

A tipografia estabelecida para o redesign é da plataforma Google Fonts. O site fornece fontes gratuitas e open-source para usos variados. A família de fontes escolhida para textos é sem serifa e se chama Roboto, desenhada por Christian Robertson. A família escolhida para títulos possui serifa e se chama Roboto Slab, também desenhada por Christian Robertson (Figura 8).

Figura 8: Roboto e Roboto Slab - Fontes utilizadas no Moodle-UFPR.

\section{$\mathrm{Aa}_{56789}^{01234} \mathbf{A a}_{56789}^{01234}$ Roboto Roboto Slab}

No que diz respeito ao uso de ícones (Figura 9), os que foram designados pela equipe de Design são também gratuitos e open-source, retirados da plataforma Google Material(Google, 2017). O site fornece diretrizes, componentes e ferramentas para auxiliar na elaboração de projetos. Existem diferentes tipos de ícones oferecidos pela plataforma e os escolhidos para o Moodle-UFPR foram os de tipo arredondado. 

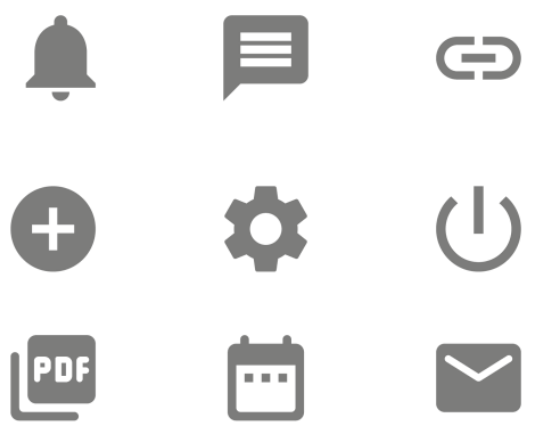
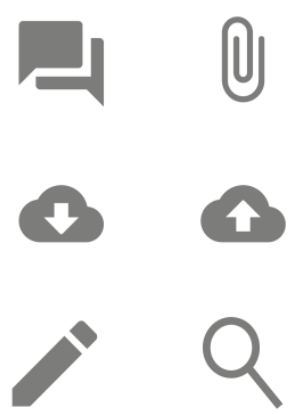

Ressalta-se que, conforme as telas foram sendo produzidas, a equipe de Design sempre esteve em contato com a Equipe CIPEAD/UFPR, a fim de que pudessem aprovar ou requisitar alterações nas telas, até que ambas as partes estivessem satisfeitas no momento.

\section{Resultados}

A figuras 10,11, 12 e 13 apresentam algumas das telas desenvolvidas para a nova versão do Moodle-UFPR, em que os conceitos de design universal e design da informação foram fundamentais.

Os estudos apresentados foram muito relevantes para o entendimento e escolha do processo de redesign que foi seguido. Levando em consideração a importância de uma plataforma mediadora do ensino a distância por meio virtual, aliado ao Design Centrado no Usuário, a estrutura e esqueleto anteriormente apresentados, buscaram seguir as premissas de um sistema: interativo; de fácil acesso e entendimento; que incluísse diversidade de usuários; e que através da organização estrutural e visual, estabelecesse um padrão e lógica para os diferentes cursos existentes.

Aplicando os elementos visuais, tendo como base os wireframes, teve-se como resultado (Figuras 10) um protótipo não funcional seguindo todas as premissas citadas. Neste redesign, o usuário poderá entender mais sobre o que é o Moodle-UFPR (Figura 10), já que a plataforma terá uma página inicial com todas as informações essenciais (juntamente com os cursos ofertados), assim como um acesso rápido e distinto para o usuário (seja ele visitante, professor ou aluno).

Ao ter acesso às páginas internas, o usuário será contemplado no mural com os cursos agora distintos por cor e padronagem (Figura 11). Cada categoria de curso, como a UFPR Híbrida por exemplo (Figura 12 e 13), seguirá uma padronização na apresentação das informações, tornando a experiência do usuário mais simples, ainda que haja densidade de conteúdo textual.

Reforça-se que, cada decisão de design da interface e design da informação no protótipo advém do que foi consolidado nas etapas anteriores. Sabe-se que sua efetividade só será garantida após testagem com os potenciais usuários do Moodle-UFPR. 
Bueno, J., Antoniolli, K. A. \& Heleno, L. L. | Moodle - UFPR: um redesign de interface centrado no usuário Figura 10: Tela protótipo do Moodle-UFPR.
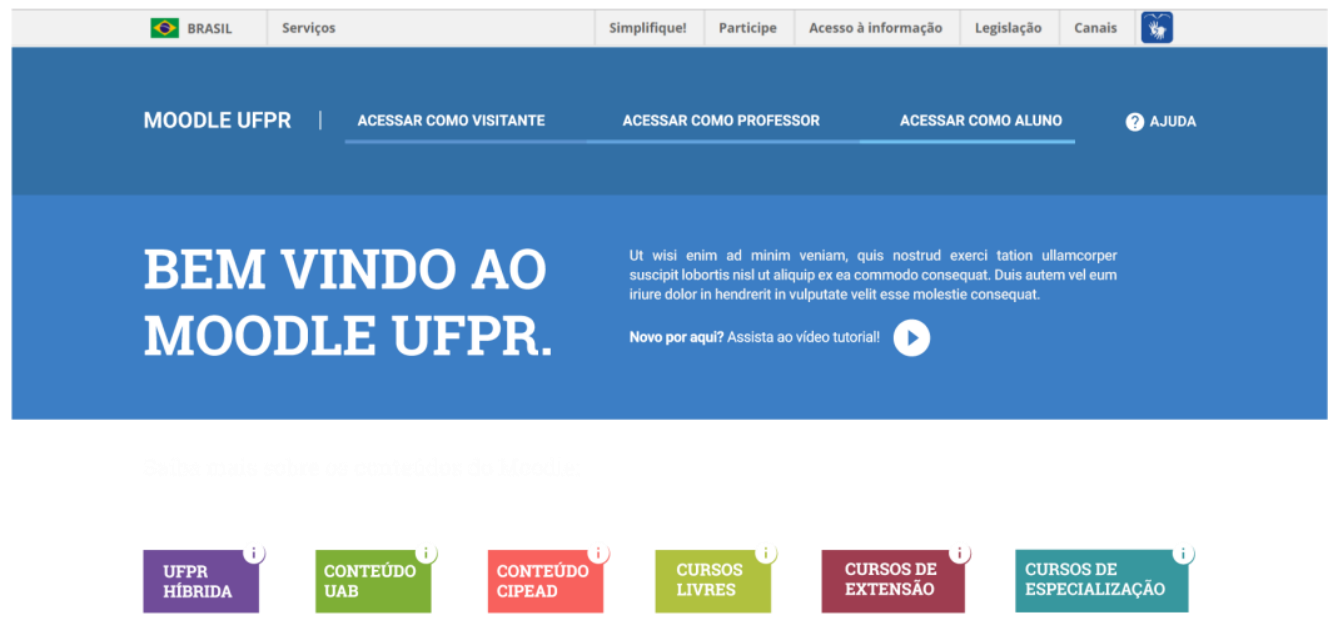

Realizaçāo:

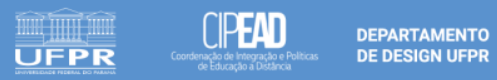

Figura 11: Tela protótipo do Moodle-UFPR.

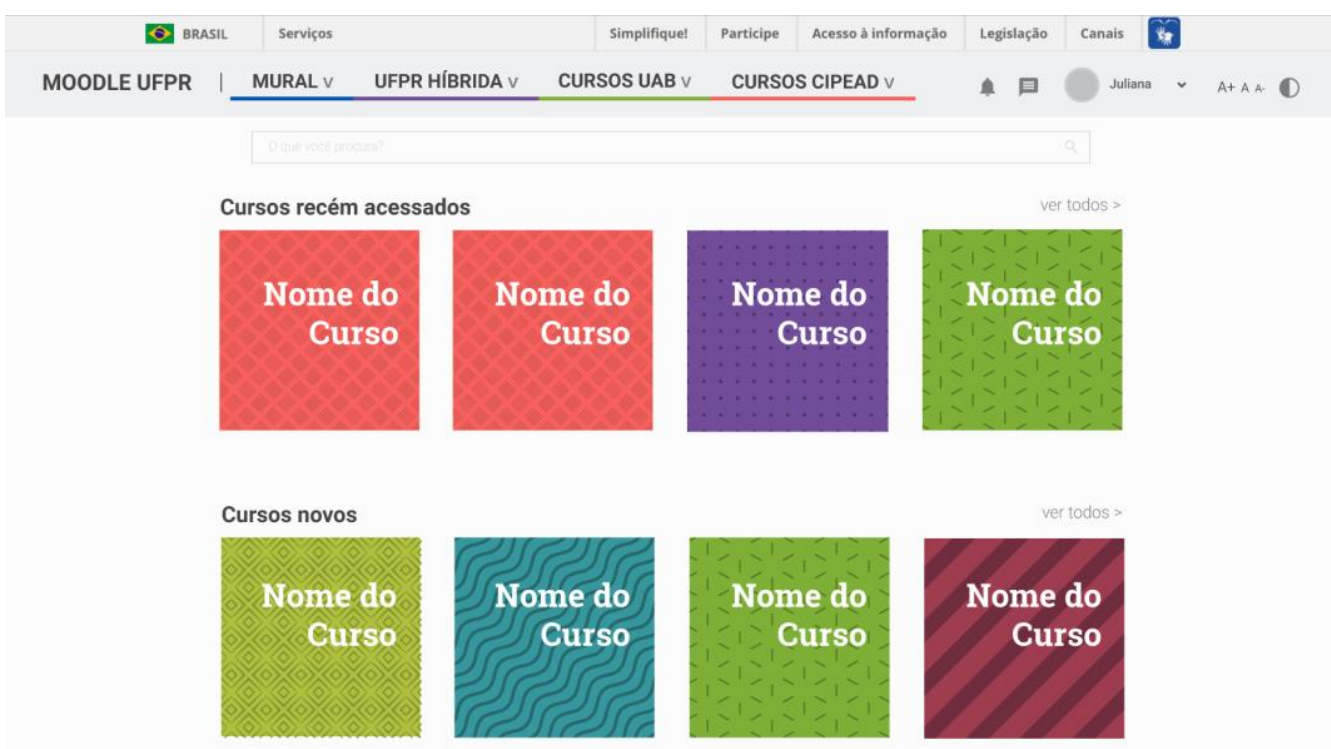

Anais do 9o Congresso Internacional de Design da Informação |CIDI 2019 
Figura 12: Tela protótipo do Moodle-UFPR.

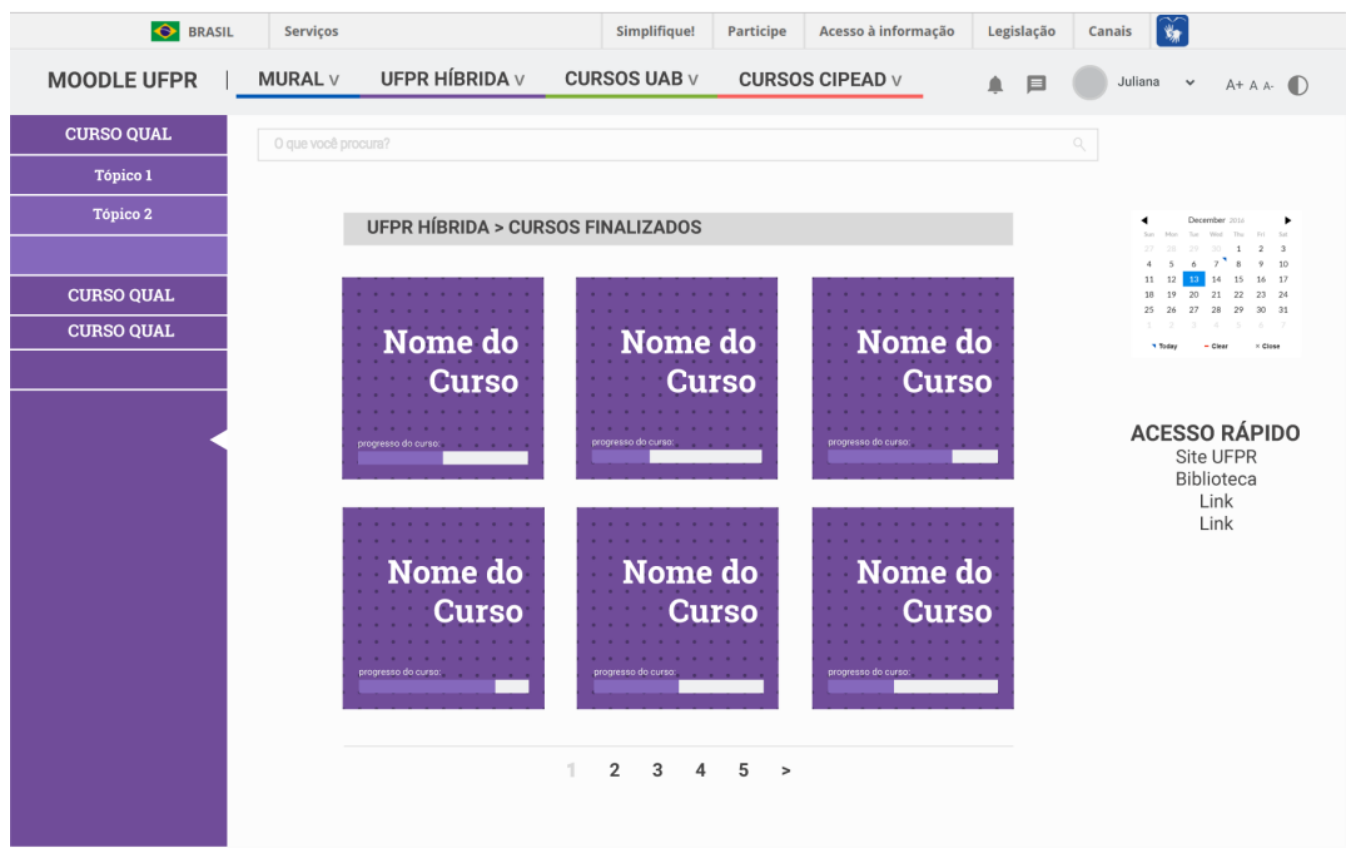

Figura 13: Tela protótipo do Moodle-UFPR.

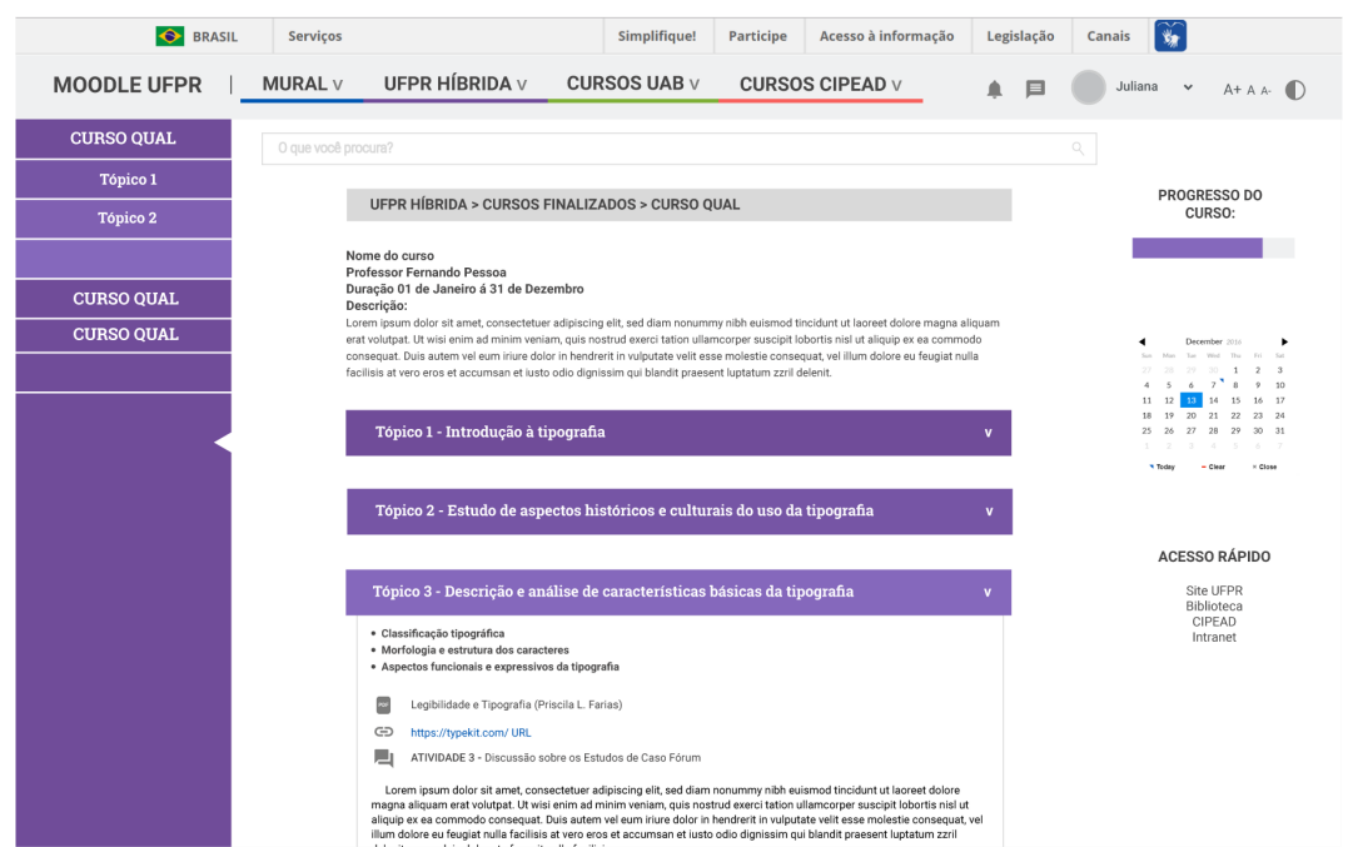

\section{Considerações finais}

A EaD é de suma importância e, cada vez mais, instituições de ensino utilizam AVAs para complementar ou aperfeiçoar alguma temática diante dos alunos. Dentre os AVAs disponíveis, o mais utilizado é o Moodle, como no caso da Universidade Federal do Paraná.

Entretanto, assim como ocorre no Moodle-UFPR atual, a interface foi desenvolvida em cima de padrões prontos já oferecidos pela plataforma, não levando em conta a diversidade de público, premissas de design da informação e de interação, muito menos, as reais 
necessidades do público que o acessa. No intuito de modificar este contexto, de um projeto envolvendo o Departamento de Design da UFPR e a CIPEAD/UFPR, o presente artigo traz o percurso para o redesign do Moodle-UFPR.

A equipe de design desenvolveu um protótipo não funcional, e um guia de estilo para ser implementado pela equipe do CIPEAD/UFPR no novo projeto de interface e interação da plataforma do Moodle-UFPR. Tendo como premissa o design centrado no usuário, o projeto teve tanto o desenvolvedor da plataforma (CIPEAD/UFPR) quanto o usuário final (discentes e docentes) envolvidos nas etapas de decisões cruciais, principalmente quanto a organização do conteúdo.

O resultado foi o protótipo de uma plataforma mais intuitiva e interativa, formada por categorização de cores, com informações simples e claras, e trazendo as ações de forma mais direta e fluída ao usuário. O próximo passo, é a implementação e teste pelos potenciais usuários (professores e alunos) com ou sem deficiência, para que o redesign efetivo seja garantido.

Além disso, o Moodle-UFPR ainda deixa caminho para futuras validações, análises e refinamentos, levando em consideração o crescimento da plataforma, diversidade de usuários e cursos no âmbito da educação a distância.

\section{Referências}

Almeida, M. E. B. (2006) Educação, ambientes virtuais e interatividade. In: SILVA, M. (Org). Educação on-line: teorias, práticas, legislação, formação corporativa. São Paulo: Loyola.

Cybis, W., Betiol, A.H., \& Faust, R. (2015) Ergonomia e Usabilidade 3a edição: Conhecimentos, Métodos e Aplicações. Novatec Editora.

Filatro, A. (2007) Design instrucional contextualizado . Editora Senac, São Paulo, Brazil.

Gabardo, P.; Quevedo, S. R. P. de; Ulbricht, V. R. (2010) Estudo Comparativo das Plataformas de Ensino-Aprendizagem. Encontros Bibli: Edição especial de sistemas de informação, Florianópolis, v. 33, n. 3, p. 65-84, 1 dez. 2010. Disponível em:

<http://www.periodicos.ufsc.br/index.php/eb/article/download/16888/15763>.

Garrett, J. J. The Elements of User Experience: User-Centered Design for the Web and Beyond. Second Edition. Aiga, 2011.

Filho, J. G. (2004) Gestalt do Objeto. 6ª ed. . São Paulo: Escrituras Editora.

Google. Material Design (2017) Disponível em: https://material.io/design/

Horn, R. (1998) Visual language: global communication for the 21th century. Washington: Macrovu Inc.

Horton S., \& Quesenbery W. (2014) A Web for Everyone: Designing Accessible User Experiences, 1ed. EUA: Rosenfeld.

ISO 9241-210 (2010) Ergonomics of human-system interaction - Part 210: Human-centred design for interactive systems.

Martin, B. \& Hanington, B. (2012) Universal Methods of Design. Beverly, MA: Rockport Publishers.

Mijksenaar, P. (1997) Visual function: an introduction to information design. Rotterdam: 010 Publishers.

Moodle (2018) Open-source learning platform. Disponível em: https://moodle.org/

Moretto, L., \& Ulbricht, V. R. (2011) Uma análise comparativa da Acessibilidade Digital da Plataforma Moodle entre as versões 1.9 e 2.0. Ambiente virtual de aprendizagem 
Bueno, J., Antoniolli, K. A. \& Heleno, L. L. | Moodle - UFPR: um redesign de interface centrado no usuário inclusivo / organizadores: Vania Ribas Ulbricht, Tarcísio Vanzin e Vilma Villarouco. Florianópolis : Pandion.352 p.

NCSU (1997) The Principles of Universal Design: Version 2.0. Disponível em: <https://projects.ncsu.edu/design/cud/about_ud/udprinciplestext. htm>.

Krueger, R. A. (1994) Focus groups: a practical guide for applied research. 2. ed. Thousand Oaks: SAGE Publications.

Lowdermilk, T. (2013) Design Centrado no Usuário: um guia para o desenvolvimento de aplicativos amigáveis. Tradução: Lúcia Ayako Kinoshita. São Paulo: Novatec.

Lupton, E. (2017) Design is storytelling. New York: Cooper- Hewitt.

Pereira, A.T.C. (2007) Ambientes Virtuais de Aprendizagem: Em em diferentes Contexto. Rio de Janeiro: Ed.Ciência Moderna.

Santos, E. (2006) O. Articulação de saberes na EAD online: Por uma rede interdisciplinar em ambientes virtuais de aprendizagem. In: SILVA, M. (Org). Educação on-line: teorias, práticas, legislação, formação corporativa. São Paulo: Loyola, pp. 219-232.

Silva, M. (2006) Educação on-line: teorias, práticas, legislação, formação corporativa. São Paulo: Loyola.

Sonza, A., Kade, A., Façanha, A., Rezende, A., Nascimento, G., Rosito, M., Bortolini, S., \& Fernandes, W. (2013) Acessibilidade e tecnologia assistiva: pensando a inclusão sociodigital de PNEs. Instituto Federal do Rio Grande do Sul, Bento Gonçalves, Brazil.

\section{Sobre o(a/s) autor(a/es)}

Juliana Bueno, Doutora, UFPR, Brasil <oieusouaju@gmail.com>

Karina de Abreu Antoniolli, Graduanda, UFPR, Brasil <antoniolli.kari@gmail.com>

Letícia Lôndero Heleno, Bacharela, UFPR, Brasil <leti.londero@gmail.com 